\title{
ARAUTOS DA FOLIA ARTE E ELEGÂNCIA NAS COMISSÕES DE FRENTE DAS ESCOLAS DE SAMBA DO RIO DE JANEIRO (1960-1980)
}

Elizeu de Miranda Corrêa (PUC-SP)

Este artigo tem como objetivo recuperar questões relacionadas à função das atuais comissões de frente das escolas de samba do Rio de Janeiro, que vivenciaram transformações relevantes entre as décadas de 1960 e 1980. Aborda as relações do papel principal exercido por esses grupos no desfile com funções equivalentes às dos arautos da Idade Média. Nessa perspectiva busco compreender os processos de produção de memória, seleção e esquecimento em relação a sua função no contexto das atuais comissões de frente e o eterno embate entre as propostas ditas tradicionais e modernas, justificando rupturas e permanências.

ESCOLA DE SAMBA, COMISSÃO DE FRENTE, ARAUTO, VELHA GUARDA. 
Neste artigo optou-se pelo estudo das comissões de frente embaladas pelo contexto das transformações promovidas no Brasil a partir de meados dos anos 50 e da gestão do presidente Juscelino Kubitschek, cujo plano de metas abriu a economia brasileira ao capital estrangeiro, instaurando nova fase no país - nesse sentido, aspectos de modernidade eram objetivos latentes de sua administração. O Rio de Janeiro deixava de ser a capital do país em função da construção de Brasília, a economia foi-se industrializando, abriram-se rodovias de integração entre os estados, favorecendo a indústria automobilística. Novas perspectivas afloravam, e o universo da escolas de samba também se reformulou com a presença de artistas oriundos do Theatro Municipal do Rio de Janeiro, o que se tornou um divisor de águas no cenário dessa manifestação popular. Por conseguinte, o sentido de modernização, como embate entre o antigo e o novo, ganhava espaço, e um novo olhar também era direcionado para a comissão de frente das agremiações. Segundo Hiram Araújo,

com o passar do tempo, a comissão se foi modernizando nos trajes, na postura, na apresentação e nos tipos de componentes. Em 1965, no Carnaval do IV Centenário, a Salgueiro colocou, como comissão de frente, Burrinhas (típicas dos folguedos) (ARAújo, 2003, p. 320).

Para elaboração deste artigo, recorreu-se a entrevistas com os atores sociais envolvidos no processo de transformação das comissões de frente, tendo a oralidade como fonte para a construção do trabalho para registrar trajetória, tensão, transformações e contradições. Nessa perspectiva, buscou-se inspiração em Paul Thompson (1992) a fim de definir os procedimentos adequados para dar forma às ideias e reconstruir o passado através de testemunhos de pessoas que vivenciaram as experiências:

Entrevistas também fornecem evidência sobre os processos [e] (...) o processo de entrevistas mostrou ser o modo mais rápido de construir um esboço de história [pois] (...) muitas vezes somente a evidência oral é que permite o estudo adequado de uma atividade (THOMPSON, 1992, p. 137).

Ao se perceber a importância dos depoimentos e relatos das pessoas do passado, constata-se que

a evidência oral pode conseguir algo mais penetrante e mais fundamental para a história. Enquanto os historiadores estudam os atores da história à distância, a caracterização que fazem de suas vidas, opiniões e ações sempre estará sujeita a ser descrições defeituosas, projeções da experiência e da imaginação do próprio historiador: uma forma erudita de ficção. A evidência oral, transformando os "objetos" de estudo em "sujeitos", contribui para uma história que não só é mais rica, mais viva e mais comovente, mas também mais verdadeira (IDEM).

Essas afirmações possibilitaram uma interpretação das evidências da história oral enquanto recurso metodológico único, deixando, portanto, à margem outros subsídios que proporcionam o conhecimento histórico.

Acredita-se que a oralidade enquanto fonte de conhecimento para o historiador oferece um leque de possibilidades e sugere um trajeto sem fronteiras, que ultrapassa os limites da análise da história oral. Elegeu-se, então, para esta pesquisa a aborda- 
gem de Alessandro Portelli (1993, p. 41-58), que entende a história oral como um gênero de discurso.

Nesse sentido, seguiu-se também Khoury (2001, p. 83),

ao trabalhar as narrativas como textos e, portanto, com um enredo, com interpretações construídas pelos sujeitos (...) com características próprias que tornam evidente o trabalho da palavra como trabalho da consciência, construindo interpretações na dinâmica social.

Segundo Portelli (1993, p. 41-58), o depoimento oral possui significado como "um evento em si mesmo", que o direciona "a uma análise que permita recuperar não apenas os aspectos materiais do sucedido, mas a atitude do narrador em relação a eventos, à subjetividade, à imaginação e ao desejo". Logo, a subjetividade no processo de narração do depoente, sua imaginação durante a fala constituem fatores que tendem a ser considerados inexatos, diferentes dos fatos históricos relatados pelos narradores, pois podem significar sonhos, desejos, anseios, esperanças e expectativas.

No entanto, cabe advertir, ficam evidentes as dificuldades para o historiador interpretar a dinâmica social da história, recuperar os fatos históricos. Diante dessas reflexões aceita-se que:

O desafio da história oral nesse sentido é mostrar, diferentemente do que costuma ser consagrado, que a memória não é apenas ideológica, mitológica e não confiável, mas sim um instrumento de luta para conquistar a igualdade social e garantir o direito às identidades (FERREIRA, 2000, p. 13).

Desse modo, acredita-se que as entrevistas realizadas com os atores sociais do universo das escolas de samba, utilizadas neste artigo, revelam e recuperam meandros da história dos depoentes, suas experiências e memórias, e imaginações de suas construções de vida, todas referentes à comissão de frente, dando luz e possibilitando novas questões. À medida que se trabalham os depoimentos, entende-se que se produz um documento escrito, e, consequentemente, se constrói uma fonte.

Ex-cenógrafo e ex-carnavalesco, Fernando Pamplona é considerado pela literatura pertinente ao tema escola de samba e pela imprensa o pioneiro na inclusão de intelectuais e de artistas nesse universo, e, portanto, o promotor da ruptura entre o tradicional e o moderno, bem como o responsável pelo impulso transformador na estética e na formatação dos desfiles das agremiações carnavalescas, e, por conseguinte, da comissão de frente.

Em 1965, Pamplona era o carnavalesco da Escola de Samba Acadêmicos do Salgueiro; em várias de suas entrevistas publicadas ele menciona a introdução das burrinhas ${ }^{1}$ na comissão de frente do Salgueiro, em plena ditadura militar e na época dos festejos do IV Centenário da Cidade do Rio de Janeiro. Nesse contexto, a inquietação estimulou a realização de uma entrevista com o carnavalesco, para tentar-se buscar algumas respostas.
1. Manuel Querino, apud Câmara Cascudo (1988, p. 155) descreve a burrinha como "um indíviduo mascarado, tendo um balaio na cintura, bem acondicionado, de modo a simular um homem cavalgando uma alimária, cuja cabeça de folha de flandres produzia o efeito". 
Ressalta Walter Benjamin (1994, p. 197), porém, que apresentar o "narrador não significa trazê-lo mais perto de nós, e sim, pelo contrário, aumentar a distância que nos separa dele", ainda que fisicamente presente, durante a realização de uma entrevista, estabelecendo um ponto de convergência com os ensinamentos de Alessandro Portelli.

Antes das considerações em torno do depoimento de Fernando Pamplona, é pertinente enfatizar que durante a entrevista o depoente, em momentos de falas e silêncios, manifestou muita emoção, reiterando o fato de que a narrativa é forma de se expressar a experiência vivida.

Nesse sentido Benjamin aponta que a narrativa vem carregada de sentimentos, visto que o narrador traz carga muito densa de seu passado e das experiências vividas. Consequentemente, ao relembrar, revive de maneira intensa o passado, uma vez que, ao ser estimulado a responder acerca de um fato, o sujeito automaticamente aciona o campo psicológico. Entretanto, o autor adverte que

nada facilita mais a memorização das narrativas que aquela sóbria concisão que as salva da análise psicológica. Quanto maior a naturalidade com que o narrador renuncia às sutilezas psicológicas, mais facilmente a história se gravará na memória do ouvinte (BENJAMIN, 1994, p. 204).

Diante do exposto, entende-se que cabe ao historiador certa afinidade com as várias formas de narrativa que trabalham com a memória, no intuito de compreender como as relações entre passado e presente convivem com o sujeito, e, portanto, permitem ao historiador reconstruir, pelos fragmentos de outrora, a história de um lugar, da forma mais natural possível, para que ela tenha fixação mais acentuada na memória do ouvinte. Benjamin (p. 198), aliás, observa que "entre as narrativas escritas, as melhores são as que menos se distinguem das histórias orais".

Assim, rememorar significa um breve olhar, focado no presente, o que não significa esquecer-se do passado, mas sim operar sobre o presente.

2. Entrevista concedida ao autor em12 de novembro de 2009 no Bar Salsa e Cebolinha, Rua Gomes Freire, 517 - Lapa - Rio de Janeiro.
Sob essa perspectiva, vejamos a narrativa de Pamplona:

nós inovamos um pouco a escola de samba. Na comissão de frente, nós inovamos quando nós pusemos (...) a burrinha e na burrinha (...) nós botamos os Dragões da Independência (...), então eu abri foi a primeira, eu acredito que tenha feito mal, em vez de existir no balanço bacana de Chico Buarque, eu botei o Dragão da Independência de burrinha. ${ }^{2}$

O depoente assume para si o pioneirismo quanto à inovação do Salgueiro, também na comissão frente, numa década em que a agremiação ditou regras para as coirmãs com relação ao processo de elaboração da estrutura do desfile. Com discurso em tom de euforia e emoção, manifestado pelo timbre de sua fala e pela expressão de seu rosto, no instante da entrevista, Pamplona rememorou ainda o fato de colocar na abertura do desfile uma representação da tradicional unidade do Exército brasileiro - 1ํ Regimento de Cavalaria do Exército, os Dragões da Independência - dançando em burrinhas. 
O feito de que Pamplona tanto se orgulhou foi realizado um ano após o golpe militar que trazia em seu bojo crise gerada pelo Governo João Goulart entre 1961 e 1964. Nesse cenário se configuravam as proezas do depoente, e o que chama a atenção em seu discurso é o sentido de que em plena ditadura militar no Brasil ele se tenha inspirado e se utilizado da manifestação popular para reforçar (supõe-se que inconsciente) o sentimento de ufanismo; entende-se, por conseguinte, que o carnavalesco demonstra certa simpatia pelos militares que haviam tomado o poder no país. Isso ganha eco quando o depoente menciona que "no tempo dos milicos, a gente tinha liberdade hoje não tem mais. (...) Eles não ligavam muito para isso não, eles ligavam para política". ${ }^{3}$

3. Ver nota 2.

Diante do exposto, pode-se questionar até que ponto mais uma vez o Estado não se teria utilizado da manifestação popular para manipular e reforçar suas intenções. A resposta pode ser imaginada a partir da ideia de que a cultura era a mola mestra para difundir e vincular a ideologia dos governos militares, de acordo com Jacira Silva de França (2009). Cabe ainda ressaltar que o samba e o futebol já eram tidos como símbolos de identidade nacional, também forjados por uma ideologia de governo, nesse caso o de Vargas.

Percebeu-se também, durante a entrevista, outro ponto que reforça o sentido tradicionalista e conservador, oculto em Pamplona: ficou evidente o sentimento de arrependimento por ter apresentado a comissão de frente do Salgueiro em 1965 de forma diferenciada e inovadora para a época - bem como, aliás, suas fortes críticas aos trabalhos performáticos desenvolvidos nas comissões de frente das escolas de samba na atualidade.

Ainda que as poucas referências sobre o tema arrisquem a reforçar a ideia de que a proposta do artista na avenida tenha sido a grande divisora de águas para o quesito comissão de frente entre o denominado estilo tradicional e a proposta moderna, ele declara: "eu esculhambei; o resto vem todo inventando atrás. Hoje a comissão de frente é uma performance; é muito mais própria na Bienal de São Paulo do que no desfile da escola de samba, é isso!". ${ }^{4}$

4. Ver nota 2.

A fim de dar mais visibilidade às reflexões de Fernando Pamplona, recorreu-se à figura da comissão de frente do GRES Acadêmicos do Salgueiro de 1965 (Figura 1); há que destacar o fato de que os princípios de organização e de profissionalização nas agremiações começavam a tomar força e a definir os padrões a serem seguidos.

A imagem dá a perceber o processo de segregação no espaço social do carnaval, organizado pela Polícia Militar do Rio de Janeiro, que fazia o cordão de isolamento do público, supostamente para separar os espectadores não pagantes ${ }^{5}$ daqueles que lotavam as arquibancadas - destinadas ao público com condições de adquirir o ingresso que dá direito à ocupação do lugar, pois, o turismo a cada ano tornava-se mais expressivo no carnaval carioca.

5. Nesse ano a Prefeitura do Rio de Janeiro "construiu degraus nos locais onde ficava o público que não comprava ingresso" (RIOTUR, 1991, p. 27). 


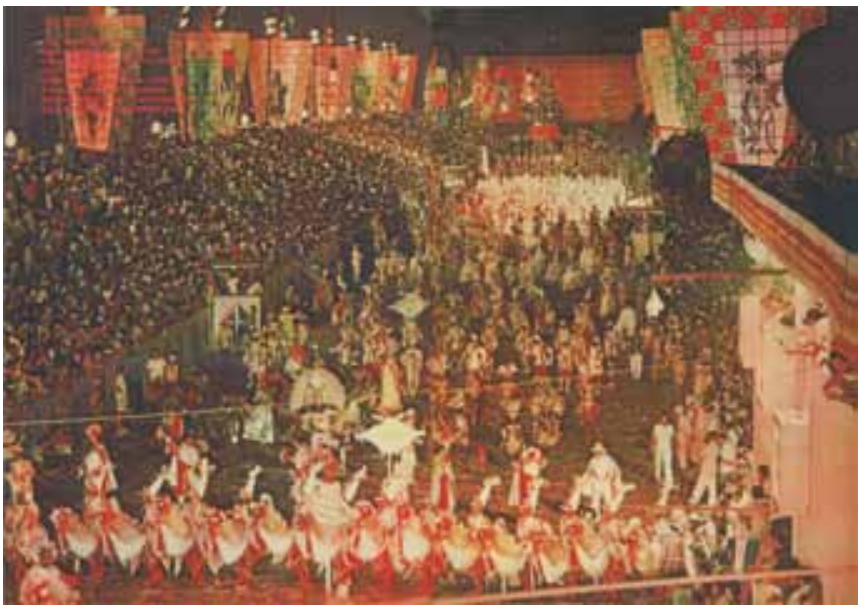

Figura 1: Comissão de frente do GRES Acadêmicos do Salgueiro, 1965

Fonte: Escolas: 0 samba fantástico. Manchete n. 674, Rio de Janeiro, 29 de março de 1965, p. 56-57.

A Polícia Militar deveria manter a segurança nacional; tal ação era objetivo fundamental do governo, e, nesse sentido, os Dragões da Independência, dançando nas burrinhas, saudavam os detentores da ordem e do poder, apresentavam a escola e pediam passagem para a "submissão" da manifestação popular, em nome da ordem e do progresso, exaltando a representação máxima da tradição do $1^{\circ}$ Regimento da Cavalaria do Exército brasileiro.

6. Em 1965, foi construída uma "passarela sobre a área do desfile para a instalação de câmeras de televisão e microfones das rádios" (RIOTUR, 1991, $p$. 276).
Ainda na década de 1960 e em praticamente toda a década de 1970, observa-se a inclusão de mulheres nas comissões de frente, sendo considerado fator importante para tanto o advento da transmissão televisiva do espetáculo. ${ }^{6}$ Cabe lembrar que no governo do general Costa e Silva, de 1967 a 1969, implantou-se o Plano de Ação Econômica do Governo - Paeg, ganhando vigor o denominado milagre brasileiro que pôs fim à recessão. Com a facilidade de crédito promovida pelo Plano, desenvolveu-se o aceleramento do consumo, principalmente de bens duráveis e os manufaturados, como os aparelhos de televisão. Sobre essa questão Jesús Martin-Barbero aponta que

o consumo não é apenas reprodução de forças, mas também produção de sentidos: lugar de uma luta que não se restringe à posse dos objetos, pois passa ainda mais decisivamente pelos usos que lhes dão forma social e nos quais se inscrevem demandas e dispositivos de ação provenientes de diversas competências culturais (MARTíN-BARBERO, 2009, p. 292).

Nesse contexto, entende-se que a escola de samba tornou-se um produto cultural, enquadrando-se, portanto, na condição de mercadoria, voltada exclusivamente para o consumo; logo, a imagem da sensualidade feminina é fruto da intenção de exaltar as mulatas brasileiras, que se tornavam uma "vitrina" para o mundo. Sobre "a inovação trazida ao desfile pela Imperatriz Leopoldinense", Nei Lopes registra: 
há alguns anos, essa escola resolveu mostrar uma comissão de frente (normalmente integrada por velhos beneméritos ou honoráveis da escola) composta de mulheres em trajes sumários. A inovação fez sucesso aos olhos de um público que não entendia ou tinha perdido o significado tradicional das comissões de frente (LOPES, 1981, p. 50-51).

É importante destacar que as intenções eram outras quando realizaram essas mudanças. Ao incluir a figura feminina na comissão de frente, até então composta exclusivamente pela figura masculina, o objetivo foi supostamente explorar a sensualidade feminina apenas na condição de corpos seminus, portanto, desprovida de massa crítica. É preciso considerar também que os resultados das transformações no âmbito global atuam de forma declarada na comissão de frente e, assim, promovem uma revolução sem precedentes.

O surpreendente é observar que o contexto dessas inserções dos corpos femininos na passarela do samba corresponde à segunda fase do feminismo, décadas de 1960 e 1970, marcando radical mudança na história das mulheres. ${ }^{7}$ Nessa perspectiva, o discurso feminista tinha como metas igualdade de direitos para mulheres e hoPriore (1997). mens, autonomia e integridade de seu corpo, elementos esses imperceptíveis na "utilização" das mulheres nos desfiles.

Sua integração na comissão de frente, entretanto, se contrapõe à luta feminista. Assim, à medida que o tempo passa e o mundo se transforma, as comissões de frente das escolas de samba também acompanham o processo de modificação e se adaptam, ainda que timidamente, através de sua permanência.

Para além de uma análise ingênua referente à imparcialidade da administração política, percebe-se ainda que havia sérios interesses por parte do "sistema" em manter a alienação e a ordem do povo em plena ditadura militar, e o reforço de "segurança nacional" disponibilizado também aos integrantes das escolas de samba estabelecia falsa impressão de bem-estar e status ao apoiar os costumes da classe menos favorecida.

Para o Estado era interessante o apoio velado ao samba e às manifestações populares, pois, além de manter a ordem necessária, a festa de Momo do Rio de Janeiro passava a ser fonte de lucro para o governo. Como observa Nei Lopes (1981, p.62) "o samba ia deixando de ser manifestação de arte popular para ser promoção turística e faturar para o Estado".

Vale observar que tais transformações, em suas especificidades, foram o início do modelo atual da comissão de frente. Compondo esse cenário, as características da chamada forma tradicional diluíam-se e perdiam força, mediante o sentido da inclusão da arte no trabalho das comissões de frente, a qual era apreendida nesse universo como proposta de modernidade (Figura 2).

De fraque e cartola cuidadosamente alinhados, com sapatos bem cuidados, destacando o brilho do couro, bengala sob o braço e marcante presença negra, os integrantes saudavam o público e caminhavam a passos lentos, destacando a elegância do con- 


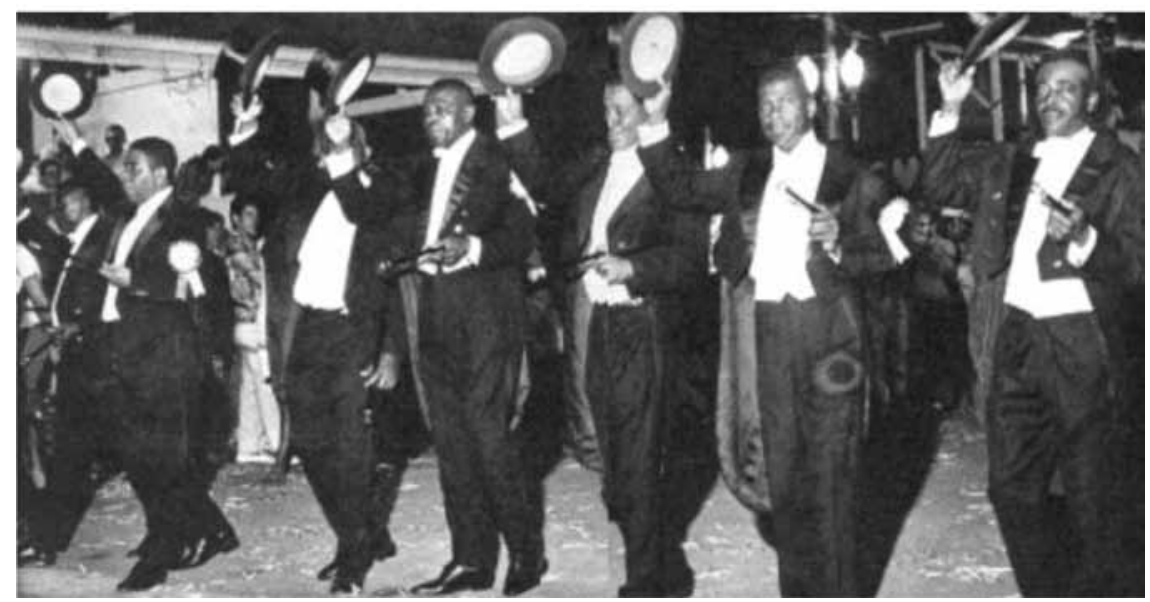

Figura 2: Na comissão de frente, ainda que se apropriando de novos elementos, os dignitários do samba, representados pela velha guarda, resistiam à presença do novo. Comissão de frente do GRES Acadêmicos do Salgueiro, 1970

Fonte: Acervo do Centro de Memória da Liesa-RJ.

junto. Nota-se também uma espécie de broche afixado ao braço esquerdo dos integrantes, acredita-se que confeccionado nas cores da agremiação, remetendo à ideia de pertencimento e de identidade, não obstante tais broches também possam ser relacionados aos símbolos ostentados nas paradas militares e nos desfiles em comemoração ao dia da independência do Brasil, demonstrando o orgulho de ser brasileiro. Nesse sentido, até onde a comissão de frente do Salgueiro novamente não estaria reforçando as insígnias do poder do governo militar, manipulando a manifestação popular?

Segundo Hiram Araújo (2003, p. 320), “Em 1978, a Mangueira trouxe duas comissões de frente. A que valia pontos era formada por mulheres, e a outra, por figuras tradicionais da escola, como Cartola, Nelson Cavaquinho, Grande Otelo e outros".

A Figura 3 reflete discursos sobre a velha guarda: Cartola sorridente, saudando o público, na condição de um dos mais consagrados compositores da música popular brasileira e ícone da Estação Primeira de Mangueira.

O traje a rigor é substituído pela fantasia que o estiliza, confeccionada em tecido brilhante, supostamente lamê; permanece a gravata borboleta, herança do traje a rigor. Coroa e manto reforçam o sentido de permanência da etnia negra como a realeza do samba. Dentro desse quadro, cabe situar o leitor diante das inovações tecnológicas na passarela do samba. Percebem-se iluminação e decoração ao longo da pista do desfile, além da cobertura das arquibancadas. Trata-se na realidade de produção nos moldes capitalistas, objetivando elevar a qualidade do carnaval que se industrializava, aproximando-o, nesse sentido, do padrão hollywoodiano, a fim de atingir dessa maneira o público mais elitizado. 


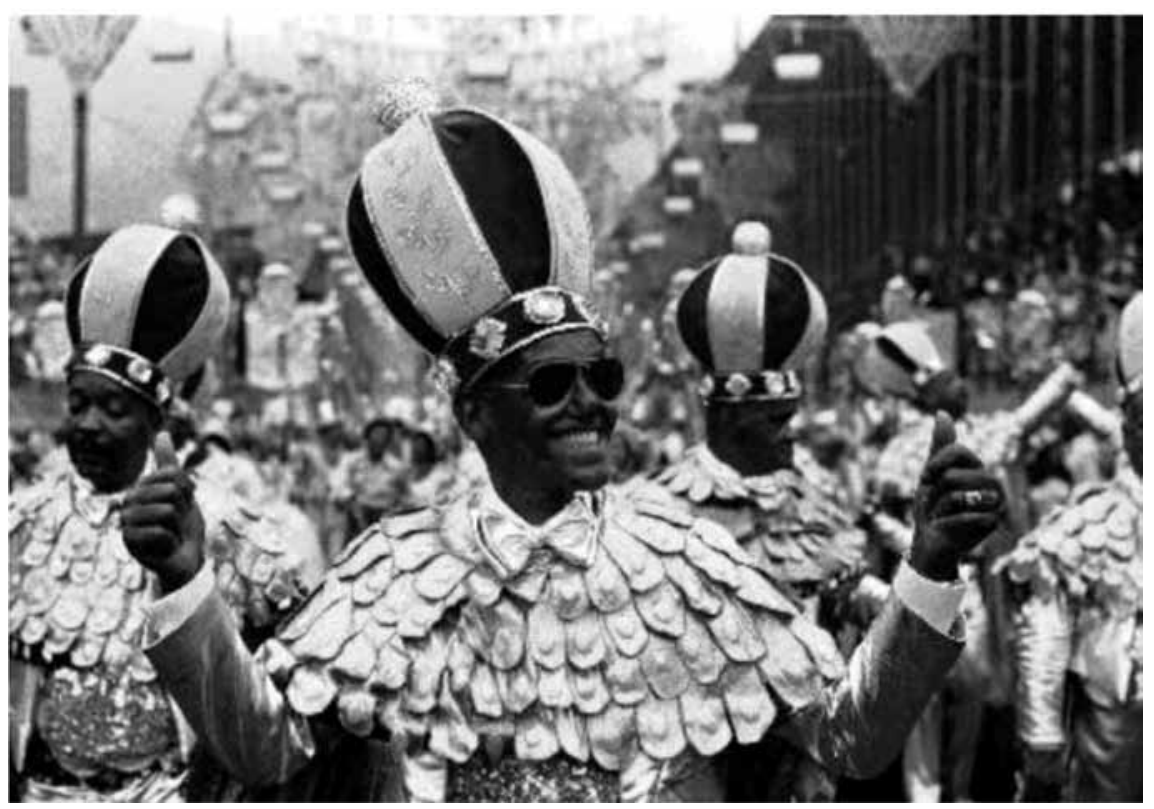

Figura 3: Compositor Cartola, na comissão de frente do GRES Estação Primeira de Mangueira, 1978

Fonte: acervo do Centro de Memória da Liesa-RJ.

Cabe, no entanto, uma questão, muito embora não levada ao limite: até quando vai permanecer essa batalha entre a velha guarda (entenda-se visão tradicional) e a atual comissão de frente, versão moderna dessa manifestação?

Alguns autores sinalizam o momento aproximado da ruptura entre a chamada proposta tradicional de desfile da comissão de frente e a denominada proposta de desfile adequada ao enredo, ou seja, estilo moderno:

A comissão de frente: originalmente era composta pelas figuras importantes da escola que desfilavam na frente da agremiação envergando a roupa típica do malandro elegante ou mesmo fraque e cartola. A partir da década de 1980, a comissão de frente foi perdendo sua função de simples apresentadora do desfile e incorporando características teatrais, tornando-se, desse modo, uma espécie de introdução ao espetáculo (FERREIRA, 2004, p. 368) [grifos meus].

José Muniz Júnior, ao discorrer sobre as transformações que foram realizadas na dinâmica das comissões de frente, remonta à década de 1970. Muniz retoma o que já havia sido abordado por autores como Nei Lopes, Eneida de Moraes, Sérgio Cabral, Hiram Araújo e outros acerca da comissão de frente, isto é, sua disposição no desfile, integrantes, missão, vestimenta, mas destaca a transição dessa forma de composição por outra mais sofisticada com roupas elegantes:

Comissão de Frente: Geralmente, essa ala é integrada por elementos elegantemente trajados, com a principal finalidade de saudar as autoridades e o público em geral. São considerados os mestres de cerimônia ou mordomos, por- 
tanto, não são obrigados a cantar ou dançar. Sua missão é a de cumprimentar em nome da agremiação, demonstrando o respeito dos sambistas pelo povo que vai assistir ao desfile. Essa "linha de frente", normalmente, reúne diretores, componentes ou até associados da escola, em número variável de nove a 15 elementos. Entretanto, essa tradição vem sendo quebrada, pois já estão sendo utilizadas como comissão de frente, alas luxuosamente fantasiadas e inclusive mulheres com trajes sumários (MUNIZ JÚNIOR, 1976, p. 178).

A preocupação em definir o que é a comissão de frente promoveu uma fossilização dessa atividade, para alguns, como Neusa Fernandes (1986), que considerou que a comissão de frente funciona como mestres de cerimônias, talvez pelo fato de saudar e cumprimentar o público em nome da agremiação com seus trajes elegantes. Para Meirelles o mestre de cerimônia é o

profissional que conduz - sempre seguindo o roteiro do Cerimonial e o script que estabelece suas "falas" - nas diversas fases do evento, se destaca pela aparência, postura e voz, ocupando lugar de evidência. A apresentação e o estilo do traje deve se adequar ao tipo de evento que apresenta como, smoking para solenidades de gala; terno ou costume escuro para a noite, nos acontecimentos sociais; conjunto de calça e blazer, sempre com gravata para as cerimônias menos formais. Em eventos esportivos pode dispensar a gravata, mantendo paletó. Recomenda-se não utilizar gravatas estampadas, paletós coloridos e tênis (2002, p. 151).

Em nossa era, ele aparece na figura do arauto. Vestido de acordo com os costumes da época anunciava a entrada dos convidados em festas da nobreza batendo três vezes um bastão sobre um batente, produzindo um som alto e seco (2008).

Reforçam-se essas ideias diante das afirmações de Maria Laura Viveiros de Castro Cavalcanti (2006, p. 57 e 58):

Os quesitos mestre-sala e porta-bandeira e comissão de frente articulam a função cerimonial que desempenham à plasticidade do visual e à dança (...). A comissão de frente inaugura o desfile saudando o público "de forma gentil e graciosa e comunicativa" (Liga 1992) ao longo de toda extensão da passarela, pedindo passagem para a sua escola.

É pertinente destacar que o papel da comissão de frente é elástico, passível de múltiplas interpretações, pelo fato de saudar o público e apresentar a agremiação no desfile. No entanto, encontrou-se eco da associação da função da comissão de frente ao posto do mestre de cerimônia e ao desempenho do arauto.

A Figura 4 sintetiza a interpretação das inovações e apropriações da comissão de frente e a batalha entre o sentido do moderno e do tradicional nesse universo. Nessa ressignificação, a presença de uma artista de grande expressão no cenário musical, a cantora Clara Nunes, apresentando a escola e saudando o público, atua como uma espécie de arauto à frente da comissão de frente caracterizada ao estilo tradicional.

Pressupõe-se que sua presença na comissão de frente seja uma tentativa de projetar a escola através do poder da imagem comercial da cantora, além, naturalmente, de 


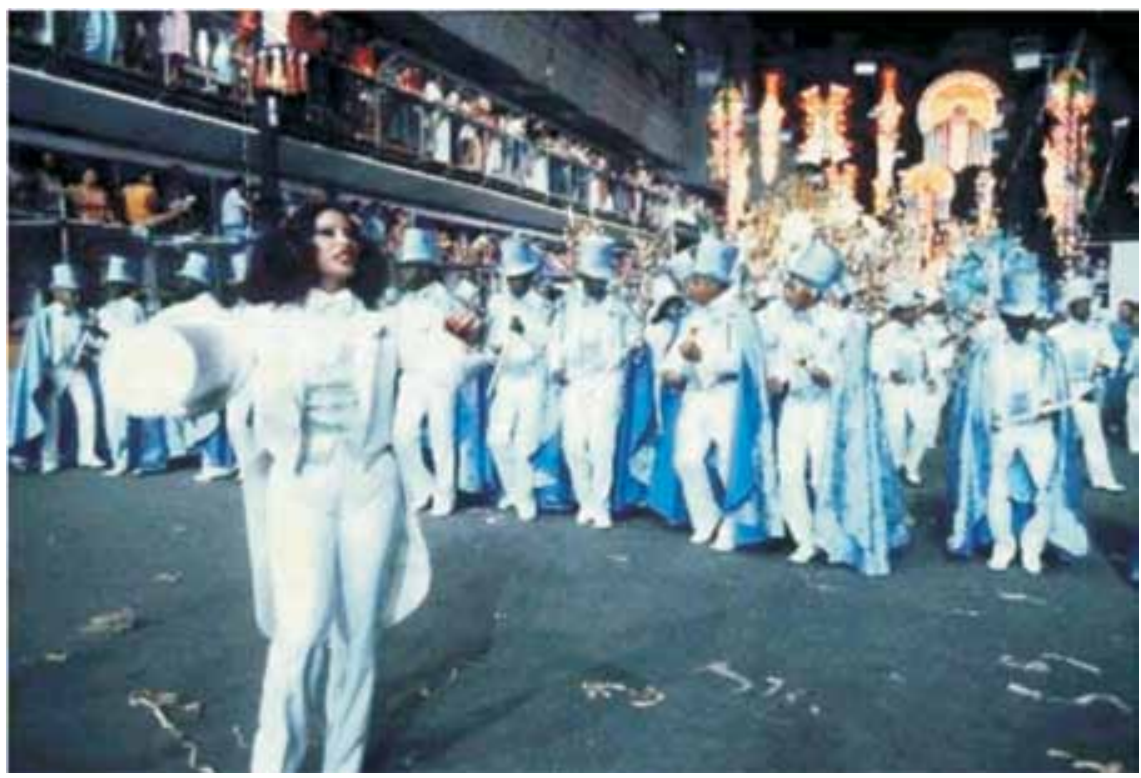

Figura 4: Comissão de frente do GRES Portela, composta pela velha guarda, com a presença da cantora Clara Nunes, 1980

Fonte: acervo do Centro de Memória da Liesa-RJ.

seus vínculos afetivos com a agremiação. Insinuava também o que viria a ser a comissão de frente moderna: espécie de prelúdio da grande ópera de rua.

Cabe ressaltar que o contexto nacional dessa época era de turbulência, período de incertezas e de valorização da informação. Inaugurava-se a nova Constituição. A presença da cantora agrega significados, sentidos e eterniza os elementos cotidianos, mais simples; é também tentativa de eternizar a velha guarda, com o manto que ainda compõe o figurino revelando o sentimento de nobreza dos detentores do poder no universo do samba carioca.

A análise das planilhas referentes às notas do quesito comissão de frente revela o papel determinante de seu traje, modelo e função. Nesse sentido, percebeu-se a manutenção de uma perspectiva tradicional de alguns julgadores em relação aos trajes como definidor do modelo a ser apresentado pelo conjunto. Assim, no Carnaval de 1987, a julgadora Regina Braga, emitiu a menor nota, ${ }^{8}$ para o GRES Acadêmicos do Salgueiro, justamente por não concordar com o traje das componentes, como observa na planilha: "Belas moças, porém o fio dental não é indumentária que prime pela criatividade. Banalização das possibilidades apresentadas pelo belo enredo da escola".
8. A nota atribuída pela julgadora à agremiação foi 7. Mapa de Julgamento, Carnaval 1987. Prefeitura Municipal do Rio de Janeiro. RIOTUR, 1987. Centro de Memória da Liesa. 
Por outro lado, a julgadora emitiu a nota máxima à comissão de frente da Escola de Samba Beija-Flor de Nilópolis reforçando e apoiando a função de cerimonial apresentada pelo conjunto, bem como idealizando tal modelo como perfeição, destacando na planilha de julgamento: "Seus mestres de cerimônia, em acordo com o enredo da escola, é proposta perfeita. Também a perfeita elegância dos gestos."

A nota máxima também foi dada pela julgadora à Estação Primeira de Mangueira, com estes comentários: "Perfeita a tradição da verde-e-rosa, na indumentária e na atitude. Também a escolha dos poetas integrantes da comissão é ótima." Percebe-se que a atitude da julgadora reforçava o sentido de comissão de frente tradicional, cujo tema era "Artistas e Velha Guarda" ao considerar perfeição o desempenho realizado pelos integrantes. Atribuiu ainda, a nota máxima à Escola de Samba Império Serrano, acrescentando na planilha de julgamento a menção: "Bela indumentária. Excelente ideia, a dos arautos. Ótima."

9. FONSECA, Maria Rodrigues. Mapa de Julgamento, Carnaval 1988. Prefeitura Municipal do Rio de Janeiro. RIOTUR, 1988. Centro de Memória da Liesa.
No ano seguinte a julgadora Marilda Rodrigues Fonseca, ${ }^{9}$ diferentemente de sua colega Regina Braga, não deu nota máxima às agremiações que se apresentaram de forma tradicional; fez a seguinte menção para o GRES Acadêmicos do Salgueiro ao Ihe atribuir nota nove: "Caráter traditivo, elegância na apresentação, formação rígida, dignidade e orgulho".

Por outro lado, fez severas críticas à Escola de Samba

Portela, à qual deu nota oito: "Segundo o que pude observar, neste quesito a escola nada acrescentou". A julgadora é clara e objetiva na justificativa do conceito atribuído à escola; ela não aceitava as propostas de trabalho de forma tradicional das comissões de frente; assim, para a Escola de Samba Mangueira, a julgadora deu nota nove, com a seguinte observação: "Apresentação tradicional, sem acréscimos".

Yaskara Manzini, pesquisadora de dança, de teatro e coreógrafa de comissão de frente em São Paulo, acredita que os anos 80 foram tempo de demarcação entre o contorno tradicional e o modelo moderno na comissão de frente da escola de samba:

A "forma tradicional" está ligada aos primórdios desta ala, quando os fundadores e "mais antigos", ou seja, a ala que hoje chamamos de Velha Guarda da agremiação, apresentavam na avenida o trabalho que desenvolviam junto a suas comunidades, enfatizando a continuidade e preservação do e no samba. Aproximadamente desde os anos 80, a Comissão de Frente passou a apresentar um espetáculo à parte dentro do próprio espetáculo, no desfile das escolas de samba, quando a tradição cedeu lugar à criação, e os integrantes da ala passaram a representar a parte inicial do enredo de suas agremiações. Tal alteração fez aparecer no universo do carnaval a figura do profissional de artes cênicas chamado coreógrafo, ou em alguns casos, do diretor teatral. Esta mutação, da tradição à criação, fez com que a Comissão de Frente abandonasse a função de somente "apontar" o desfile (apresentar) e abarcasse a comunicação de um tema (representar) (MANZINI, 2006). 
É fato que a colaboração dos profissionais das artes cênicas foi fundamental para a implantação de novas linguagens das comissões de frente, que passaram a assumir o papel de se comunicar e de interagir com a plateia, ao anunciar o enredo e ao encenar um pequeno espetáculo, eliminando, portanto, a figura dos atores sociais da chamada velha guarda e cedendo espaço para a expressão artística. Nesse movimento percebemse novas posições. Assim, são várias as indicações provenientes da comissão de frente, não havendo lugar fixo para as inovações dos artistas que deram personalidade nova a essa prática cultural.

Sendo assim, percebe-se a complexidade conceitual e metodológica referente às comissões de frente, cuja trajetória converge com os campos da política, da economia, do poder, da sociedade e etc., se entrecruzando a aspectos simbólicos, estéticos e gestuais. Nesse sentido a comissão de frente dos séculos XIX e XXI entram em cena como lugar de investigação. Na realidade a comissão do século XIX revela-se espaço de dominação social e política; as comissões do século XXI podem ser interpretadas como território diluído e de múltiplos significados e simbolizações.

\section{REFERÊNCIAS BIBLIOGRÁFICAS}

ARAÚJO, Hiram. Carnaval: seis milênios de história. Rio de Janeiro: Gryphus, 2003.

BENJAMIN, Walter. O narrador. Considerações sobre a obra de Nikolai Leskov. In Magia e técnica, arte e política: ensaio sobre literatura e história da cultura. Tradução Sérgio Paulo Rouanet. 7. ed. São Paulo: Brasiliense, 1994.

CAVALCANTI, Maria Laura Viveiros de Castro. Carnaval carioca: dos bastidores ao desfile. Rio de Janeiro: UFRJ, 2006.

FERNANDES, Neusa. Síntese da história do carnaval carioca. Rio de Janeiro: Governo do Estado do Rio de Janeiro/Secretaria de Estado de Ciência e Cultura/Departamento Geral de Cultura/Instituto Estadual do Patrimônio Cultural/Divisão de Pesquisa da Manifestação Cultural, 1986.

FERREIRA, Felipe. O livro de ouro do carnaval brasileiro. Rio de Janeiro: Ediouro, 2004.

FERREIRA, Marieta de Moraes; FERNANDES, Tania Maria; ALBERTI, Verena (orgs.). História oral: desafios para o século XXI. Rio de Janeiro: Editora Fiocruz-Casa de Oswaldo Cruz/ Fundação Getúlio Vargas-CPDOC, 2000.

FRANÇA, Jacira Silva de. Indústria cultural e ditadura militar no Brasil dos anos 70 . Revista Acadêmica Eletrônica Sumaré. 2. ed, São Paulo, 2009. Disponível em: <www.sumare. edu.br/raes/edicoes/ed02/industria_cultural-jacira.pdf>. Acesso em: 17 jul. 2010.

KHOURY, Yara Aun. Narrativas orais na investigação da história social. Projeto História. Revista do Programa de Estudos Pós-Graduados em História e do Departamento de História da PUC-SP, n. 22. São Paulo, jun. 2001.

LOPES, Nei. O samba na realidade... A utopia da ascensão social do sambista. Rio de Janeiro: Codecri, 1981.

MANZINI, Yaskara. Comissão de Frente. São Paulo, 2006. Disponível em: <www.carnavalpaulista.com>. Acesso em: 18 ago. 2008.

MARTíN-BARBERO, Jesús. Dos meios às mediações: comunicação, cultura e hegemonia. Tradução Ronald Polito e Sérgio Alcides. 6. ed. Rio de Janeiro: Editora UFRJ, 2009. 
MEIRELLES, Gilda Fleury. Protocolo e cerimonial: normas, ritos e pompa. 2 ed. São Paulo: STS, 2002, p. 151.

. O papel do mestre de cerimônias. Disponível em: <http://www.sinprorp. org.br>. Acesso em: 18 ago. 2008.

MUNIZ JÚNIOR, José. Do batuque à escola de samba. São Paulo: Símbolo, 1976.

PAES, Maria Helena Simões. A década de 60: rebeldia, contestação e repressão política. 4 ed. São Paulo: Ática, 1997. Série Princípios.

PORTELLI, Alessandro. Sonhos ucrônicos: memórias e possíveis mundos dos trabalhadores. In Projeto História. Revista do Programa de Estudos Pós-Graduados em História e do Departamento de História da PUC-SP, n.10. São Paulo, dez. 1993.

PRIORE, M. L. M. História das mulheres no Brasil. São Paulo: Contexto, 1997.

RIOTUR, Empresa de Turismo do Município do Rio de Janeiro S.A. Memória do carnaval. Rio de Janeiro: Oficina do Livro, 1991.

THOMPSON, Paul. A voz do passado: história oral. Tradução de Lólio Lourenço de Oliveira. 3 ed. Rio de Janeiro: Paz e Terra, 1992.

Elizeu de Miranda Corrêa é doutorando e mestre em história pela Pontifícia Universidade Católica de São Paulo, com a dissertação As múltiplas faces da comissão de frente no contexto da ópera de rua (1928-1999), pós-graduado pela Faculdade Paulista de Artes em comunicação em arte-educação; história da arte: teoria e crítica; e psicopedagogia e arte-terapia; e graduado em educação artística com habilitação plena em artes plásticas pela Universidade de Mogi das Cruzes, SP. 